\title{
Modeling Extinction Risk of Endemic Birds of Mainland China
}

\author{
Youhua Chen \\ Department of Zoology, University of British Columbia, Vancouver, BC, Canada V6T $1 Z 4$ \\ Correspondence should be addressed to Youhua Chen; haydi@126.com
}

Received 5 July 2013; Revised 20 October 2013; Accepted 4 November 2013

Academic Editor: Hirohisa Kishino

Copyright (C) 2013 Youhua Chen. This is an open access article distributed under the Creative Commons Attribution License, which permits unrestricted use, distribution, and reproduction in any medium, provided the original work is properly cited.

\begin{abstract}
The extinction risk of endemic birds of mainland China was modeled over evolutionary time. Results showed that extinction risk of endemic birds in mainland China always tended to be similar within subclades over the evolutionary time of species divergence, and the overall evolution of extinction risk of species presented a conservatism pattern, as evidenced by the disparity-throughtime plot. A constant-rate evolutionary model was the best one to quantify the evolution of extinction risk of endemic birds of mainland China. Thus, there was no rate shifting pattern for the evolution of extinction risk of Chinese endemic birds over time. In a summary, extinction risk of endemic birds of mainland China is systematically quantified under the evolutionary framework in the present work.
\end{abstract}

\section{Introduction}

Global biodiversity crisis is emerging and increasingly recognized in recent years for biologists [1]. Terrestrial environment has been widely affected by humans [2] and habitats of terrestrial species are facing irreplaceable transformation which in term would pose great threats to the survival of these species. It is said that worldwide organisms are now facing the sixth mass extinction period $[3,4]$. In such a context, ecologists have high pressures to facilitate conservation measures so as to better offer refuges for conserving species. One of these measures is to understand the evolution and drivers of extinction risk of species $[5,6]$.

Birds are an important vertebrate taxonomy and deserve to be allocated more conservation efforts because of their popularity for common people [7-9]. Understanding and modeling extinction risk of birds would be an important step to set up corresponding conservation strategies. There are growing interests focusing on the diversification, biogeography, conservation, and extinction risk of bird species [10-13].

In recent years, one of the trends in conservation biology is to sufficiently incorporate evolutionary information for the purpose to evaluate the impacts of species history on structuring species' contemporary distribution [14], conservation priorities $[15,16]$, or threatened risk $[2,17,18]$. One rationale for modeling extinction risk of species through phylogenetic tree is that the underlying ecological variables associated with extinction risk of species are related to evolutionary history of species, for example, distributional ranges [14, 19], morphological traits [20], physiological tolerance spectrum of environmental conditions [21], and others.

China is one of the megabiodiverse countries over the world [22]. There are many previous studies working on the systematics, ecology, and conservation of birds in China $[13,16,23,24]$. However, understanding the extinction risk of vertebrate taxa of China from an evolutionary perspective has never been seen in any of these previous literatures. As such, in the present study, I explore the extinction risk of endemic birds of mainland China by analyzing the evolution of risk over the available species phylogenetic tree.

\section{Materials and Methods}

The list of the endemic birds of mainland China was gathered from previous studies [23, 25-27] and World Bird Database (http://avibase.bsc-eoc.org/). Threatened status of each species was collected from IUCN Red List database 
(http://www.iucnredlist.org/). The following categories and associated abbreviations were used: EN (endangered), VU (vulnerable), NT (near threatened), and LC (least concerned). One species Strix davidi did not have any records in the IUCN Red List, while another two species Caprimulgus centralasicus and Leucosticte sillemi were listed in the category of DD (data deficient). All of them were excluded for subsequent analyses. Finally, another species (Ficedula beijingnica) was found not to be included in the tree files of an online database described below. As such, in the present study, 48 endemic birds were included for the analyses (Table 1).

The phylogenetic relationship of these birds was extracted from the BirdTree.org database (http://www.birdtree.org/), which was derived from a full phylogeny of the global bird species in a previous study [28]. 3000 trees for the possible phylogenetic affinities of these 48 endemic birds were retrieved and the resultant consensus tree with average branch lengths was obtained using DendroPy Python library [29]. Molecular dating of the tree was fulfilled using a penalized likelihood method [30]. The resultant dated tree was used for all subsequent analyses and was available as the supplemental material of the study (see Supplementary Material available online at http://dx.doi.org/10.1155/2013/639635).

I followed some previous studies to model extinction risk of species $[2,18]$. In detail, first, I assigned a discrete integer to each of the IUCN categories as follows: EN (1), VU (2), NT (3), and LC (4). Then, I applied the disparity through time (DTT) [31] to model the pattern of IUCN threatened status of species over different clades of the endemic bird phylogeny. DTT is the standardized mean pairwise distance between species $[2,31]$. When the disparity of species is more remarkable between than within clades, DTT would be close to 0 towards the contemporary time and high DTT values are usually found at the time points near the root of the tree, implying that threatened status of species within a specific subclade tends to be similar. In contrast, when the disparity is more remarkable within clades, DTT should approach 1 towards the contemporary time and high DTT values are located at time points closed to the tips of the tree, implying that threatened status of species within a specific clade tends to vary greatly. For any time point, when the observed DTT value is higher than the expected one (on the randomized null curve), trait conservatism is suggested. In contrast, when the observed DTT value lies below the expected one on the null curve, trait overdispersion was suggested. As such, DTT index provided a way to understand the evolutionary paths of extinction risk of species along the evolutionary history. DTT was calculated from the extinction risk classes of endemic birds using "geiger" package [32] under R environment [33] with 1000-time randomization test.

I also applied different evolutionary models to model the evolution of threatened risk of species [18]. In specific, the following models were used to fit the evolution of extinction risk of species: Delta, linearChange, twoRate and null models. Detailed information about these models [18] for characterizing the temporal patterns of extinction risk of species were presented in Table 2. During the modeling, the equal-rate transition model was assumed. Model selection was performed using Akaike Information Criteria (AIC) [34]. The lower AIC the model has, the better it is.

\section{Results}

As showed in Figure 1, disparity within clades above the null line indicated that extinction risk of species tends to be similar within both old and young clades (indicating phylogenetic conservatism within subclades). In particular, there was a large difference between the observed and null DTT under randomization when evolutionary time window moves towards current time (Figure 1).

Although the two-rate shifting model had the lowest AIC value $(\mathrm{AIC}=125.46)$ (Table 3$)$, it was not considerably different from the AIC value (AIC $=126.34$ ) for the null model which assumes a single constant rate. Also, the twoRate model had a breakpoint at evolutionary time 0.013 , which is almost identical to the starting point of the phylogenetic tree (hence becomes very unrealistic). Moreover, the twoRate model has one more parameter in comparison to that of the constant-rate model. Therefore, the constant-rate evolutionary rate model could not be rejected and should be retained as the best one to quantify the evolution of extinction risk of endemic birds of mainland China.

\section{Discussion}

The present short report showed that extinction risk of endemic birds of mainland China showed a conservatism pattern over evolutionary history (Figure 1). Moreover, the relative high DTT values were found at time points near the root, indicating that extinction risk of endemic birds tends to be similar as long as they are in the same subclade. At last, it was observed that the constant-rate evolutionary model is the best one to quantify the evolution of extinction risk of endemic birds of mainland China.

It was found that angiosperm and vertebrate species showed many fundamental differences at evolutionary perspectives. For example, it was found that the less threatened taxa are found in more diverse clades for vertebrates $[35,36]$, while the more threatened species are present in more diverse clades for plants [2]. In the present study, it was further found that vertebrates and plants can be different at the aspects of the evolutionary models for best quantifying trait evolution. A recent study working on African angiosperm species showed that Delta model was most favored [18], while in my study, the constant-rate model was the best one to explain evolution of extinction risk of endemic birds of China.

However, it shares some similarities for the evolution of extinction risk between bird and angiosperm species. For example, as mentioned above, there exists a large difference between the observed and null DTT under randomization when evolutionary time approaches current time. This implies that "late-bust" model is applicable to explain the evolution of extinction risk of bird species, being similar to that for angiosperm species in the Cape region of Africa [2]. 
TABLE 1: List of endemic bird species of China and associated IUCN categories used in the present study.

\begin{tabular}{|c|c|c|c|c|}
\hline Order & Family & Species & Common name & IUCN \\
\hline Galliformes & Phasianidae & Arborophila ardens & Hainan Partridge & VU \\
\hline Galliformes & Phasianidae & Arborophila gingica & White-necklaced Partridge & NT \\
\hline Galliformes & Phasianidae & Arborophila rufipectus & Sichuan Partridge & $\mathrm{EN}$ \\
\hline Galliformes & Phasianidae & Lophophorus lhuysii & Chinese Monal & $\mathrm{VU}$ \\
\hline Galliformes & Phasianidae & Alectoris magna & Przevalski’s Partridge & $\mathrm{LC}$ \\
\hline Galliformes & Phasianidae & Tragopan caboti & Cabot's Tragopan & $\mathrm{VU}$ \\
\hline Galliformes & Phasianidae & Syrmaticus ellioti & Elliot's Pheasant & NT \\
\hline Galliformes & Phasianidae & Syrmaticus reevesii & Reeves's Pheasant & $\mathrm{VU}$ \\
\hline Galliformes & Phasianidae & Tetraophasis obscurus & Verreaux's Monal-Partridge & $\mathrm{LC}$ \\
\hline Passeriformes & Certhiidae & Certhia tianquanensis & Sichuan Treecreeper & NT \\
\hline Passeriformes & Muscicapidae & Phoenicurus alaschanicus & Przevalski's Redstart & NT \\
\hline Passeriformes & Leiothrichidae & Garrulax davidi & Plain Laughingthrush & $\mathrm{LC}$ \\
\hline Passeriformes & Leiothrichidae & Babax koslowi & Tibetan Babax & NT \\
\hline Passeriformes & Sittidae & Sitta yunnanensis & Yunnan Nuthatch & NT \\
\hline Passeriformes & Leiothrichidae & Garrulax bieti & White-speckled Laughingthrush & VU \\
\hline Passeriformes & Sylviidae & Chrysomma poecilotis & Rufous-tailed Babbler & LC \\
\hline Passeriformes & Aegithalidae & Aegithalos fuliginosus & Sooty Bushtit & LC \\
\hline Passeriformes & Corvidae & Perisoreus internigrans & Sichuan Jay & VU \\
\hline Passeriformes & Sylviidae & Paradoxornis paradoxus & Three-toed Parrotbill & LC \\
\hline Passeriformes & Sylviidae & Paradoxornis conspicillatus & Spectacled Parrotbill & LC \\
\hline Passeriformes & Sylviidae & Paradoxornis przewalskii & Przevalski’s Parrotbill & VU \\
\hline Passeriformes & Sylviidae & Paradoxornis zappeyi & Grey-hooded Parrotbill & VU \\
\hline Passeriformes & Corvidae & Podoces biddulphi & Biddulph's Ground Jay & NT \\
\hline Passeriformes & Leiothrichidae & Garrulax elliotii & Elliot's Laughingthrush & LC \\
\hline Passeriformes & Cisticolidae & Rhopophilus pekinensis & Chinese Hill Warbler & $\mathrm{LC}$ \\
\hline Passeriformes & Leiothrichidae & Garrulax sukatschewi & Snowy-cheeked Laughingthrush & VU \\
\hline Passeriformes & Aegithalidae & Leptopoecile elegans & Crested Tit-warbler & LC \\
\hline Passeriformes & Fringillidae & Carpodacus roborowskii & Tibetan Rosefinch & LC \\
\hline Passeriformes & Urocynchramidae & Urocynchramus pylzowi & Przevalski’s Finch & LC \\
\hline Passeriformes & Fringillidae & Carpodacus eos & Stresemann's Rosefinch & LC \\
\hline Passeriformes & Pellorneidae & Alcippe variegaticeps & Golden-fronted Fulvetta & VU \\
\hline Passeriformes & Pellorneidae & Alcippe striaticollis & Chinese Fulvetta & LC \\
\hline Passeriformes & Phylloscopidae & Phylloscopus hainanus & Hainan Leaf Warbler & VU \\
\hline Passeriformes & Phylloscopidae & Phylloscopus kansuensis & Gansu Leaf Warbler & LC \\
\hline Passeriformes & Phylloscopidae & Phylloscopus emeiensis & Emei Leaf Warbler & LC \\
\hline Galliformes & Phasianidae & Bonasa sewerzowi & Chinese Grouse & NT \\
\hline Passeriformes & Leiothrichidae & Garrulax lunulatus & Barred Laughingthrush & $\mathrm{LC}$ \\
\hline Passeriformes & Leiothrichidae & Garrulax maximus & Giant Laughingthrush & $\mathrm{LC}$ \\
\hline Passeriformes & Oriolidae & Oriolus mellianus & Silver Oriole & $\mathrm{VU}$ \\
\hline Passeriformes & Paridae & Parus davidi & Père David's Tit & LC \\
\hline Passeriformes & Emberizidae & Emberiza koslowi & Tibetan Bunting & NT \\
\hline Passeriformes & Emberizidae & Latoucheornis siemsseni & Slaty Bunting & LC \\
\hline Passeriformes & Leiothrichidae & Liocichla omeiensis & Emei Shan Liocichla & $\mathrm{VU}$ \\
\hline Passeriformes & Paridae & Parus superciliosus & White-browed Tit & $\mathrm{LC}$ \\
\hline Galliformes & Phasianidae & Chrysolophus pictus & Golden Pheasant & $\mathrm{LC}$ \\
\hline Passeriformes & Paridae & Parus venustulus & Yellow-bellied Tit & $\mathrm{LC}$ \\
\hline Galliformes & Phasianidae & Crossoptilon auritum & Blue Eared Pheasant & LC \\
\hline Galliformes & Phasianidae & Crossoptilon mantchuricum & Brown Eared Pheasant & VU \\
\hline
\end{tabular}


TABLE 2: Detailed description of alternative evolutionary models used for modeling the extinction risk of endemic birds of China.

\begin{tabular}{|c|c|}
\hline Model name & Model description \\
\hline Delta & $\begin{array}{c}\text { Delta }<1 \text { describes that the evolution rate of extinction risk of species } \\
\text { occurs rapidly early in the history of a clade and then slows through time. } \\
\text { Delta }>1 \text { describe an increasing evolution rate of extinction risk of species } \\
\text { through time. Delta }=0 \text { is identical to a Brownian motion model. }\end{array}$ \\
\hline LinearChange & $\begin{array}{l}\text { This model assumes that that evolution rate of extinction risk of species } \\
\text { should change linearly overtime. If the rate is increased linearly up to the } \\
\text { present time, then the fitting slope of the linear relationship is positive. In } \\
\text { contrast, if the evolutionary rate is decreased linearly over the time, then } \\
\text { the fitting slope should be negative. No change on the evolutionary rate } \\
\text { implies that the fitting slope is zero. }\end{array}$ \\
\hline TwoRate & $\begin{array}{l}\text { This model allows that the evolution rate of extinction risk of species shifts } \\
\text { to a new value at some time point over the phylogeny (if the new evolution } \\
\text { rate is larger than 1, evolution is believed to increase, otherwise decrease). } \\
\text { Before and after the shifting point, the evolutionary rates are kept constant. }\end{array}$ \\
\hline Null & $\begin{array}{l}\text { This model assumes a global constant evolutionary rate for extinction risk. } \\
\text { Thus, only a single constant value is returned when fitting the null model. }\end{array}$ \\
\hline
\end{tabular}

TABLE 3: Estimated parameters of alternative evolutionary models which have been fitted onto the evolution of extinction risk for endemic birds of China.

\begin{tabular}{lcccc}
\hline Models & Log-likelihood & $q$ & Parameters & AIC \\
\hline Delta & -63.12 & -1.49 & 0.527 & 128.24 \\
LinearChange & -63.11 & -0.617 & 2.27 & 128.22 \\
TwoRate & -60.73 & -0.47 & $B=0.013, E=72.20$ & 125.46 \\
Null & -63.17 & 1.09 & - & 126.34 \\
\hline
\end{tabular}

$B$ : breakpoint; $E$ : the second rate; $q$ denotes the equal transition rate among the categories of extinction risk. AIC: Akaike Information Criteria.

My present study may not be generalized to the situation when taking nonendemic avian taxa into consideration. Sampling issue is very sensitive for phylogenetic comparative studies [37, 38]. As such, for future perspectives, it would be of broad implication to analyze a more comprehensive dataset by including all bird species found in mainland China so as to better quantify the evolution of threatened risk of birds.

There are a suite of limitations of the present study. First, the sampling of endemic birds of China is still incomplete. I cannot obtain either the phylogenetic positions or detailed distributional information of som other endemic bird species. Hence, they are not included in the present study, which in turn drives the conclusions of the present study to become biased more or less. The omission of nonendemic species might further lead to a bias in bias the present results, although their distributional ranges are out of the territory of China. Second, species extinction rates could be related to a variety of complicated factors, for example, the contemporary habitat conditions, climatic variability, historical contingency, and level of disturbances that the species is facing. As such, modeling of species extinction risk from an evolutionary perspective might not be of full help to elucidate the extinction mechanisms of species driven by anthropogenic disturbance.

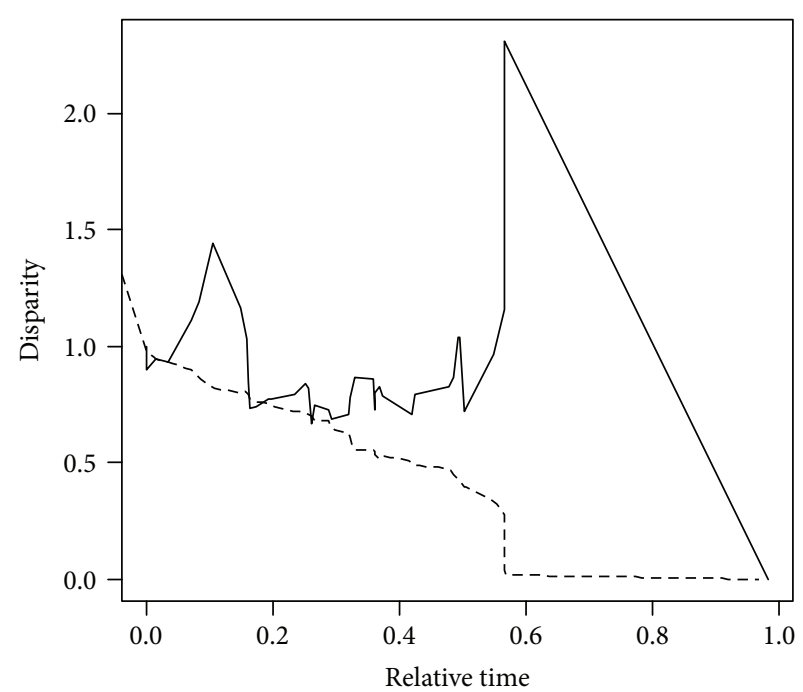

FIGURE 1: Disparity through time plot of extinction risk of endemic birds of China. The solid line is the observed curve for the endemic bird phylogeny, while the dashed line denotes the simulated curve under a 1000-randomization process. For the relative time in the $x$ axis, 0 means the root of the clade, while 1 means the present time.

\section{Acknowledgments}

The present study was supported by the University of British Columbia and China Scholarship Council.

\section{References}

[1] C. Rahbek and R. K. Colwell, "Biodiversity: species loss revisited," Nature, vol. 473, no. 7347, pp. 288-289, 2011.

[2] T. J. Davies, G. F. Smith, D. U. Bellstedt et al., "Extinction risk and diversification are linked in a plant biodiversity hotspot," PLoS Biology, vol. 9, no. 5, Article ID e1000620, 2011. 
[3] A. D. Barnosky, N. Matzke, S. Tomiya et al., "Has the Earth's sixth mass extinction already arrived?" Nature, vol. 471, no. 7336, pp. 51-57, 2011.

[4] D. B. Wake and V. T. Vredenburg, "Are we in the midst of the sixth mass extinction? A view from the world of amphibians," Proceedings of the National Academy of Sciences of the United States of America, vol. 105, no. 1, pp. 11466-11473, 2008.

[5] R. May, J. Lawton, and N. Stork, "Assessing extinction rates," in Extinction Rates, J. Lawton and R. May, Eds., pp. 1-24, Oxford University Press, Oxford, UK, 1995.

[6] D. P. Faith, "Threatened species and the potential loss of phylogenetic diversity: conservation scenarios based on estimated extinction probabilities and phylogenetic risk analysis," Conservation Biology, vol. 22, no. 6, pp. 1461-1470, 2008.

[7] M. Zmihorski, J. Dziarska-Palac, T. Sparks, and P. Tryjanowski, "Ecological correlates of the popularity of birds and butterflies in internet information resources," Oikos, vol. 122, pp. 183-190, 2013.

[8] P. Prokop and J. Fancovicova, "Does colour matter? The influence of animal warning coloration on human emotions and willingness to protect them," Animal Conservation, vol. 16, no. 4, pp. 458-466, 2013.

[9] Y. H. Chen, "Prioritizing avian conservation areas in China by hotspot scoring, heuristics and optimisation," Acta Ornithologica, vol. 42, no. 2, pp. 119-128, 2007.

[10] F. He, "Area-based assessment of extinction risk," Ecology, vol. 93, pp. 974-980, 2012.

[11] R. E. Ricklefs, "Global variation in the diversification rate of passerine birds," Ecology, vol. 87, no. 10, pp. 2468-2478, 2006.

[12] A. B. Phillimore, C. D. L. Orme, R. G. Davies et al., "Biogeographical basis of recent phenotypic divergence among birds: a global study of subspecies richness," Evolution, vol. 61, no. 4, pp. 942-957, 2007.

[13] Y. H. Chen, "Avian biogeography and conservation on Hainan Island, China," Zoological Science, vol. 25, no. 1, pp. 59-67, 2008.

[14] N. Cooper, R. P. Freckleton, and W. Jetz, "Phylogenetic conservatism of environmental niches in mammals," Proceedings of the Royal Society B, vol. 278, no. 1716, pp. 2384-2391, 2011.

[15] C. Tucker, M. Cadotte, T. Davies, and T. Rebelo, "Incorporating geographical and evolutionary rarity into conservation prioritization," Conservation Biology, vol. 26, pp. 593-601, 2012.

[16] Y. Chen, "Conservation priority for endemic birds of mainland China based on a phylogenetic framework," Chinese Birds, vol. 4, pp. 248-253, 2013.

[17] B. Daru, K. Yessoufou, L. Mankga, and T. Davies, "A global trend towards the loss of evolutionarily unique species in mangrove ecosystems," PLoS One, vol. 8, Article ID e66686, 2013.

[18] K. Yessoufou, B. Daru, and T. Davies, "Phylogenetic patterns of extinction risk in the Eastern Arc Ecosystems, an African biodiversity hotspot," PLoS One, vol. 7, no. 10, Article ID e47082, 2012.

[19] Y. Chen, "A phylogenetic subclade analysis of range sizes of endemic woody see plant species of China: trait conservatism, diversification rates and evolutionary models," Journal of Systematics and Evolution, vol. 51, no. 5, pp. 590-600, 2013.

[20] L. J. Harmon, J. B. Losos, T. Jonathan Davies et al., "Early bursts of body size and shape evolution are rare in comparative data," Evolution, vol. 64, no. 8, pp. 2385-2396, 2010.

[21] M. E. K. Evans, S. A. Smith, R. S. Flynn, and M. J. Donoghue, "Climate, niche evolution, and diversification of the "bird-cage" evening primroses (Oenothera, sections Anogra and Kleinia)," American Naturalist, vol. 173, no. 2, pp. 225-240, 2009.
[22] Y. Chen and J. Bi, "Biogeography and hotspots of amphibian species of China: implications to reserve selection and conservation," Current Science, vol. 92, no. 4, pp. 480-489, 2007.

[23] F. Lei, J. Lu, Y. Liu, Y. Qu, and Z. Yin, "Endemic bird species to China and their distribution," Current Zoology, vol. 48, pp. 599-610, 2002.

[24] Y. Wang, S. Chen, and P. Ding, "Testing multiple assembly rule models in avian communities on islands of an inundated lake, Zhejiang Province, China," Journal of Biogeography, vol. 38, no. 7, pp. 1330-1344, 2011.

[25] F. Lei and T. Lu, China Endemic Birds, Science Press, Beijing, China, 2006.

[26] F. M. Lei, G. A. Wei, H. F. Zhao, Z. H. Yin, and J. L. Lu, "China subregional avian endemism and biodiversity conservation," Biodiversity and Conservation, vol. 16, no. 4, pp. 1119-1130, 2007.

[27] Y. Zhang, "Endemic birds of China," Bulletin of Biology, vol. 39, pp. 22-25, 2004.

[28] W. Jetz, H. Thomas, J. Joy, K. Hartmann, and A. Mooers, "The global diversity of birds in space and time," Nature, vol. 491, pp. 444-448, 2012.

[29] J. Sukumaran and M. T. Holder, "DendroPy: a Python library for phylogenetic computing," Bioinformatics, vol. 26, no. 12, pp. 1569-1571, 2010.

[30] M. J. Sanderson, "Estimating absolute rates of molecular evolution and divergence times: a penalized likelihood approach," Molecular Biology and Evolution, vol. 19, no. 1, pp. 101-109, 2002.

[31] L. J. Harmon, J. A. Schulte II, A. Larson, and J. B. Losos, “Tempo and mode of evolutionary radiation in iguanian lizards," Science, vol. 301, no. 5635, pp. 961-964, 2003.

[32] L. J. Harmon, J. T. Weir, C. D. Brock, R. E. Glor, and W. Challenger, "GEIGER: investigating evolutionary radiations," Bioinformatics, vol. 24, no. 1, pp. 129-131, 2008.

[33] R Development Core Team, R: A Language and Environment forStatistical Computing, R Foundation for Statistical Computing, Vienna, Austria, 2011, http://www.R-project.org/.

[34] H. Akaike, "Information theory as an extension of the maximum likelihood principle," in Proceedings of the 2nd International Symposium on Information Theory, B. Petrov and F. Csaki, Eds., pp. 276-281, Akademiai Kiado, Budapest, Hungary, 1974.

[35] A. Purvis, P. M. Agapow, J. L. Gittleman, and G. M. Mace, "Nonrandom extinction and the loss of evolutionary history," Science, vol. 288, no. 5464, pp. 328-330, 2000.

[36] G. J. Russell, T. M. Brooks, M. M. Mckinney, and C. Gregory Anderson, "Present and future taxonomic selectivity in bird and mammal extinctions," Conservation Biology, vol. 12, no. 6, pp. 1365-1376, 1998.

[37] T. A. Heath, S. M. Hedtke, and D. M. Hillis, "Taxon sampling and the accuracy of phylogenetic analyses," Journal of Systematics and Evolution, vol. 46, no. 3, pp. 239-257, 2008.

[38] S. Poe, "Sensitivity of phylogeny estimation to taxonomic sampling," Systematic Biology, vol. 47, no. 1, pp. 18-31, 1998. 

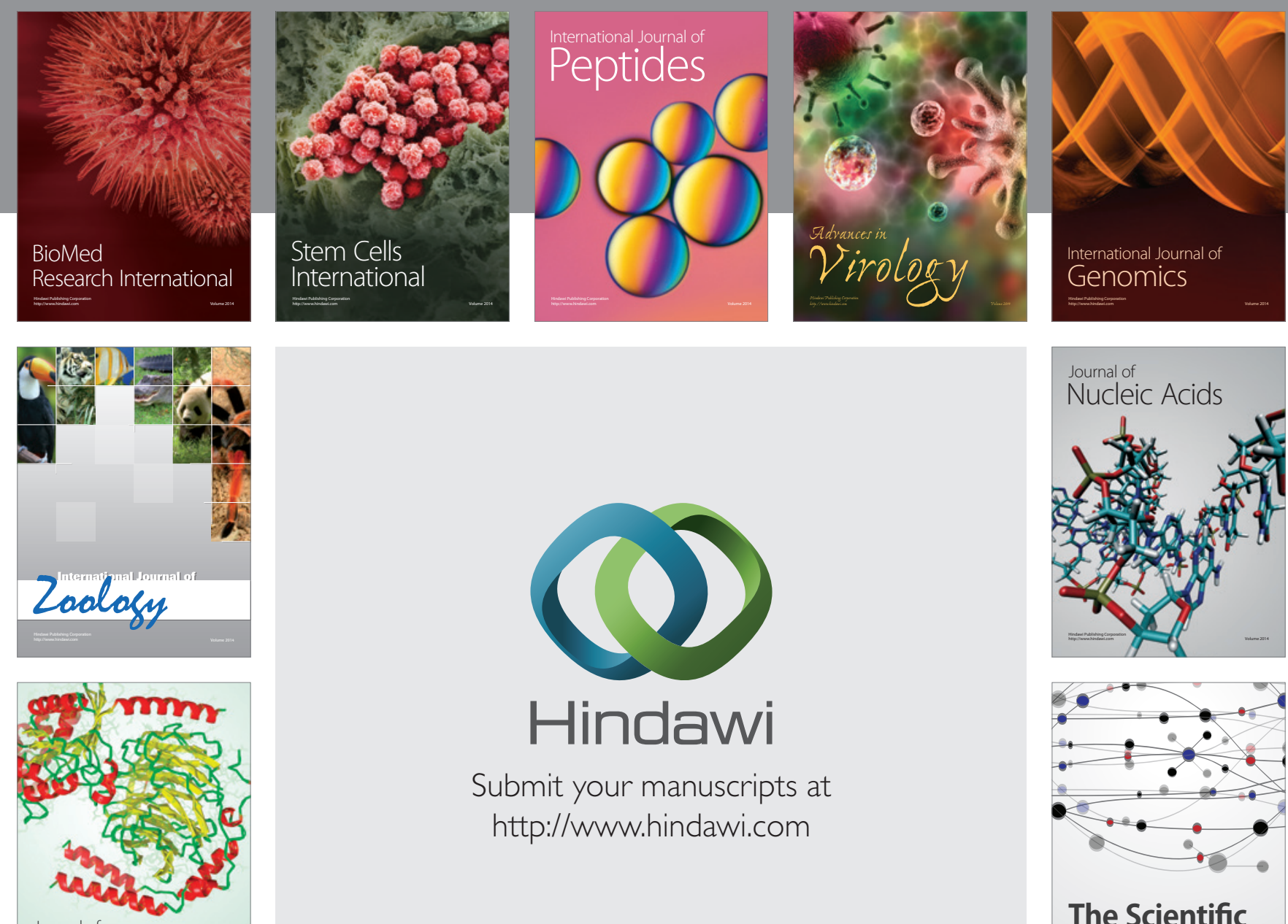

Submit your manuscripts at

http://www.hindawi.com

Journal of
Signal Transduction
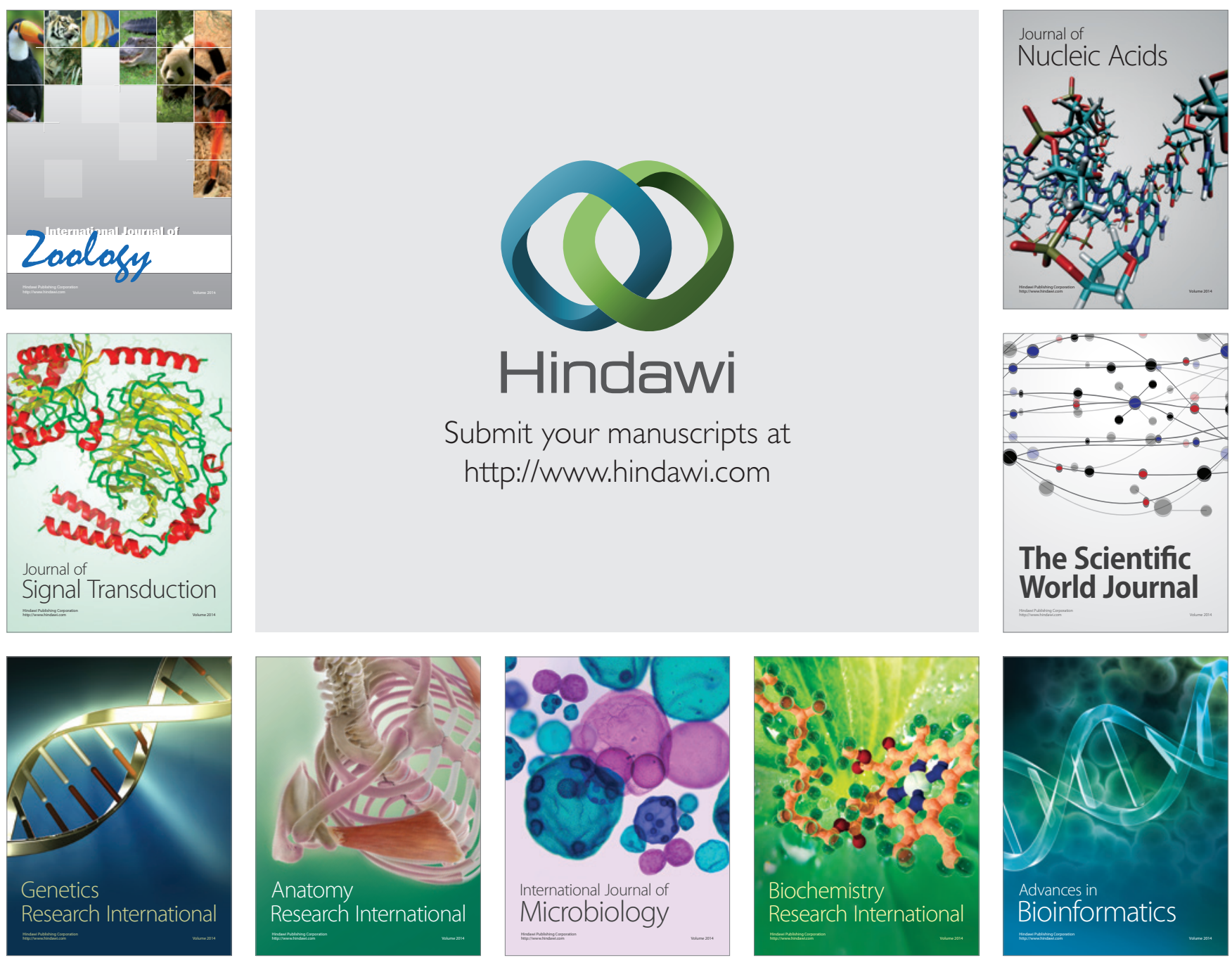

The Scientific World Journal
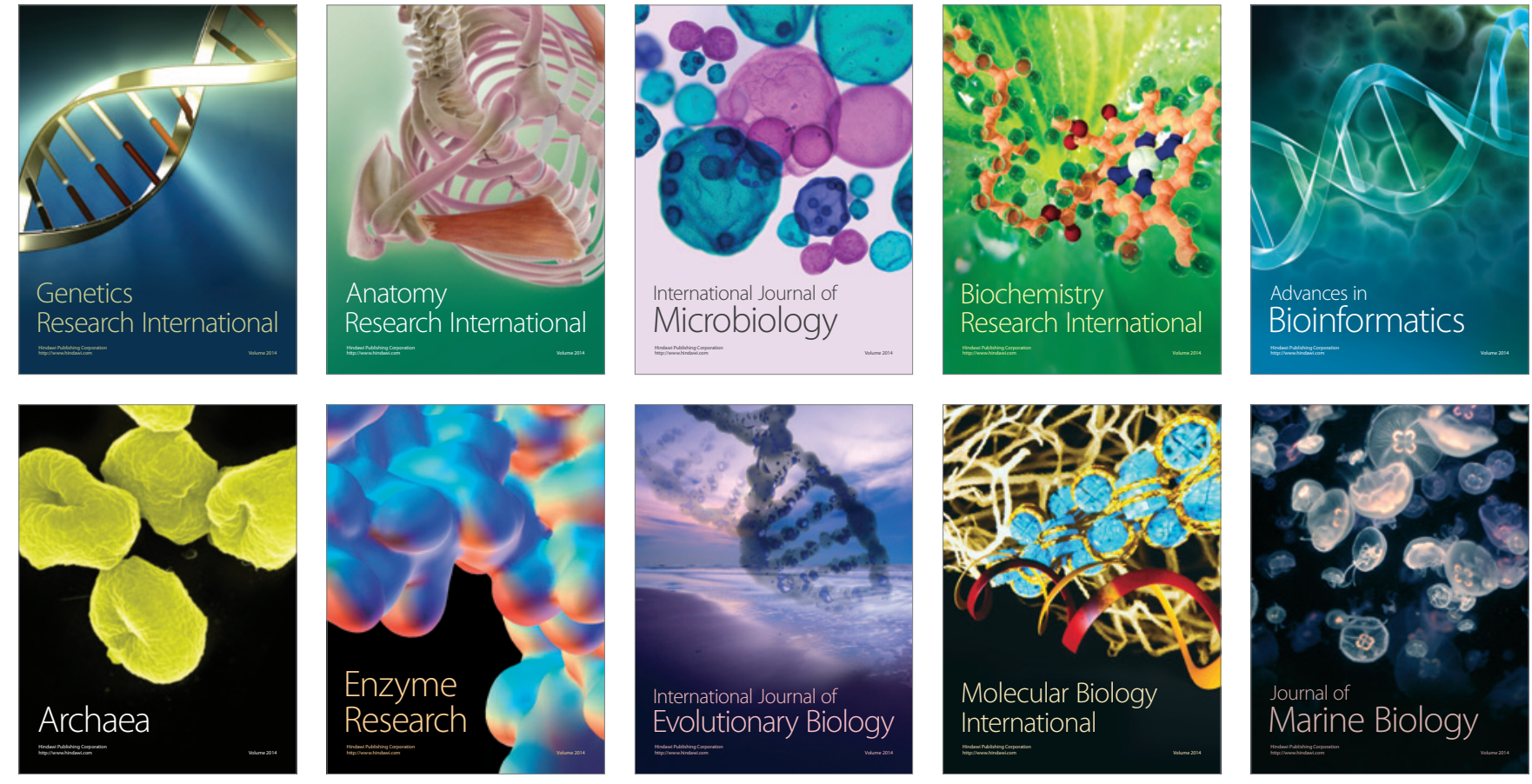